\title{
ENCONTROS ENTRE MODA E ANTROPOLOGIA: INÍCIOS, DEBATES E PERSPECTIVAS
}

Filomena Silvano ${ }^{1} \&$ Solange R. Mezabarba ${ }^{2}$ NOVA-FCSH, Lisboa, Portugal / SENAI-CETIQT, Rio de Janeiro, Brasil

Este artigo busca aproximar o olhar em direção à moda como objeto de pesquisa, análise e reflexão no campo da antropologia. A complexidade do tema dirige o debate pelas vias da transdisciplinaridade, num esforço de enriquecer e trazer clareza à discussão. Autores que se posicionam no campo da filosofia, da sociologia, da semiologia e da linguística dialogam com a antropologia, perpassando problemáticas como a da construção das identidades e a da relação com o tempo. Além disso, busca-se resgatar reflexóes que trazem para o debate recente a moda como corolário da imitação e da distinção, da performatividade, das formas de construção do corpo, das dinâmicas socioeconômicas e da materialidade. De forma a abordar a cronologia dos encontros entre a antropologia e os estudos da moda, o texto parte dos inicios (primeira metade do século XX), passando por alguns dos debates atuais e, por fim, assinalando as perspetivas que os novos trabalhos vêm dar ao campo.

Palavras-chave: moda, imitação, distinção, corpo, performance, materialidade

We're all born naked and the rest is drag.

RuPaul

Ao longo do século XX, a moda foi considerada como um fenómeno associado ao mundo urbano e à modernidade, mas cuja origem remonta às práticas do vestir das elites europeias nascidas do capitalismo mercantil. Esse ponto de vista, que a afastava à partida das geografias procuradas pelos etnógrafos, tornou o seu estudo, no seio da Antropologia, marginal. Apesar disso, houve antropólogos que escreveram, logo no início do século, sobre a moda, tendo questionado

1 Faculdade de Ciências Sociais e Humanas, Universidade Nova de Lisboa e Centro em Rede de Investigação em Antropologia (CRIA-FCSH). Contato: fsilvano@fcsh.unl.pt.

2 Faculdade de Design de Moda do SENAI-CETIQT, Centro de Tecnologia da Indústria Química e Têxtil. Contato: solange_riva@hotmail.com. 
duas das características que lhe eram então atribuídas: a mudança permanente e a presença exclusiva nas sociedades ocidentais. A moda continuou, entretanto, ainda que de forma marginal, a ser objeto de reflexão antropológica até aos nossos dias. Alguns dos textos escritos por antropólogos durante o século XX e nas duas primeiras décadas do século XXI dialogaram com a produção académica da sua época, tendo alguns deles acabado por se constituir como referências no interior do campo de estudo mais alargado que engloba hoje os fashion studies e os dress studies. Foi o caso, como tentaremos demonstrar ao colocá-los em diálogo com as propostas de outros autores, de textos de Edward Sapir, Alfred Louis Kroeber, Leroi-Gourhan, Marshall Sahlins, Daniel Miller, Susanne Kuchler, Annette B. Weiner, Grant McCracken, Joanne B. Eicher, Karen Hansen, Giulia Mensitieri, Lisa Rofel, Sylvia J. Yanagisako e Alexandra Verschueren.

\section{EM DESACERTO COM O TEMPO}

A “Theory of moral sentiments", publicada em 1759 por Adam Smith, é uma das primeiras obras onde surge uma reflexão sobre a moda, sendo nela formulado um ponto de vista que mais tarde será chamado de trickle-down theory:

Como é da nossa natureza admirar, e consequentemente imitar, os ricos e os poderosos, é a eles que cabe estabelecer ou guiar aquilo a que chamamos a moda. As suas roupas são as roupas na moda, a linguagem usada na sua conversação, o estilo na moda, o seu ar e o seu porte, a maneira de ser na moda. (Adam Smith, citado por Hammen e Simmenauer 2017: 115).

Durante a segunda metade do século XIX, vários autores vão abordar a moda referindo-se também ao facto de, em consequência da imitação pelas classes mais baixas e da vontade de distinção das classes mais altas, ela fazer, de forma repetida, um percurso social descendente. ${ }^{3}$ Herbert Spencer, em 1854, no trabalho intitulado "Manners and Fashion", trata a moda como imitação no sentido de reverenciar. $\mathrm{O}$ autor, no entanto, admite que a democratização nas sociedades teria impacto nessa dinâmica, prevendo, então, que a potência para a imitação se esvaziaria num ambiente de "igualdade". Alguns anos depois, em 1887, Durkheim refere-se à forma, que classifica de "engenhosa", como o jurista alemão Von Jhering pensa a moda:

A verdadeira causa é social: deve-se à necessidade que têm as classes superiores de se distinguirem exteriormente das classes inferiores. Como estas, pelo seu lado, tendem sempre a imitar as primeiras, a moda difunde-se na sociedade pela via do contágio. Mas, por outro lado, como ela perdeu todo o seu valor uma vez adoptada por todo o mundo, ela está condenada, pela sua natureza, a renovar-se sem interrupção. (Durkheim 1887:57)

Gabriel de Tarde, em 1890, usa a moda - que, aos seus olhos, tem na imitação algo inerente ao comportamento de grupo, e, portanto, fortalece as relações sociais - como um fenómeno exemplar para pensar a sociedade. Com uma abordagem menos comprometida com os segmentos sociais, Tarde descreve a prática da imitação de duas maneiras - a que toma a forma

3 A proposta genérica do Trickle-down será retomada, também para pensar a moda, por Thorstein Veblen (primeira edição, 1899) e Pierre Bourdieu (1979). Embora possa ser explicativa de uma parte dos fenómenos que ocorrem no mundo da moda, a teoria foi posta em causa, com base: 1) em múltiplos exemplos etnográficos que demonstram que a moda também se constitui através de movimentos de Trickle-up (Polhemus 1978); 2) em estudos etnográficos feitos no mundo da moda que demonstram que o processo de criação do novo se organiza no interior do próprio mundo da moda (Blumer 1969); 3) em propostas que sinalizam a presença da imitação no sentido lateral trickle-cross (Lipovetsky 1987; Featherstone 2007). 
do costume, uma reprodução do passado num território específico, e a que se torna moda, uma imitação no presente não localizada, mas uma imitação, de certa maneira, comedida (não mudam as saias, mas os seus comprimentos).

"Die Mode", ${ }^{4}$ de Georg Simmel, é um texto que podemos colocar no interior de uma genealogia que integra os textos atrás referidos, sendo hoje frequentemente considerado como seminal para os estudos da moda. Nele, Simmel afirma que a moda permite, dada a introdução regular da novidade nos modos de vestir, que as classes dominantes se distingam em permanência das outras classes, inventando novas práticas sempre que as antigas sejam por elas imitadas. Seguir a moda é imitar um modelo - e nesse sentido a moda responde à necessidade que cada indivíduo tem de se integrar socialmente -, mas é também distinguir-se e diferenciar-se face àquelas pessoas que não seguem esse mesmo modelo. "A moda não é senão uma forma da vida social entre muitas outras, que permite conjugar num mesmo agir unitário a tendência para a igualização social e a tendência para a distinção individual, para a variação" (Simmel 1988 : 91). Para o autor, a moda é "um puro produto das necessidades sociais", ela existe, no interior de uma sociedade de classes, para manter, ao mesmo tempo, a coesão no interior das classes detentoras do poder e a distinção destas face às outras. $\mathrm{O}$ mecanismo da igualização vs distinção pode, no entanto, funcionar também em sociedades sem classes:

Em casos em que a estrutura social não conhece camadas sobrepostas, a moda mostra bem até que ponto o fator de separação - junto com o fator de imitação - é constitutivo da sua essência; ela toma então frequentemente conta de camadas contíguas. Nalguns povos ditos naturais, grupos vizinhos muito próximos, tendo condições de vida exatamente idênticas, inventam por vezes modas estritamente distintas, marcando cada um desses grupos através desse meio tanto a sua coesão interna como a sua diferença externa. (Simmel 1988: 95-96)

Para Simmel, a moda não é uma forma social exclusiva das sociedades capitalistas, mas é nelas que ela se assume mais plenamente, e só existirá enquanto a sociedade precisar de conjugar os mecanismos de igualização/ agregação, com os de distinção/separação. ${ }^{5}$

Em 1931, Edward Sapir publicou, na "Encyclopaedia of the Social Sciences VI", um texto referente à entrada "Fashion". Inicia-o, definindo a moda como sendo "um costume mascarado de um afastamento face ao costume”. Essa espécie de contradição interna explica-se, segundo ele, porque "a maioria dos indivíduos normais têm o desejo consciente ou inconsciente de romper, de alguma maneira, com a fidelidade demasiado literal ao costume estabelecido" (Sapir 2017:124-125). As pessoas que seguem a lógica de funcionamento da moda dão-se conta de que existe, implícito na própria moda, um problema que resulta da necessidade de conciliar a liberdade individual com a conformidade social. Definindo assim a moda, Sapir torna claro que ela permite dar resposta a uma dificuldade presente na vida em sociedade: conciliar a afirmação e a expressão das individualidades e das diferenças com a integração social. A moda consegue o feito de inserir na própria normatividade do costume a possibilidade de colocar em causa a norma vigente.

Ao tentar compreender a moda, Sapir e Simmel referem-se, no essencial, ao mesmo mecanismo - aquele que permite que a moda reúna e distancie em simultâneo - mas os dois pensadores diferem na forma como pensam as razões da sua existência. Para Sapir, a origem

4 Utilizamos aqui a tradução francesa publicada, em 1988, numa coletânea de textos de Georg Simmel intitulada "La tragédie de la culture". Nela se indica, como primeira data de publicação do texto, 1895.

5 Também aqui se aproximando de Spencer. 
do mecanismo da moda não se prende, como propõe Simmel, com a diferenciação necessária à dominação de classe, mas antes com a necessidade de encontrar uma resposta cultural para o facto universal de existirem desejos individuais de mudança, cujas expressões têm por base sistemas de significação inconscientes, característicos de cada cultura. De certa forma, Sapir, que cruzava a linguística com a antropologia, inaugurou a ideia de estudar a moda como sendo uma forma de expressão/comunicação que tem por base um sistema próprio de significações. Essa ideia, que talvez possamos considerar como sendo o primeiro contributo antropológico para o estudo da moda, foi retomada a partir dos anos 1960 por autores do campo da semiologia, destacando-se, entre eles, Roland Barthes e Umberto Eco.

Em "Système de la Mode", publicado pela primeira vez em 1967, Roland Barthes inclui, em apêndice, um pequeno texto intitulado "Histoire et diachronie de mode", em que faz referência à obra "Three centuries of women's dress fashion”, de Alfred Kroeber e Jane Richardson, publicada em 1940. Resultando de uma investigação que teve por base um corpus (que se estende de 1749 a 1936) de gravuras de moda representando roupas femininas, o texto defende que um olhar mais distanciado no tempo demonstra que as variações repentinas da moda estão inseridas em ciclos longos que se repetem e que as relativizam. Para Barthes, o facto, revelado pela investigação de Kroeber e Richardson, de as variações de moda obedecerem a ciclos repetitivos que se manifestam na longa duração, mostra que a moda possui uma lógica de funcionamento que lhe é interna e, de certo modo, independente das condições sociológicas do momento em que ocorrem as mudanças. Segundo Barthes, a moda estrutura-se ao nível da sua história e desestrutura-se ao nível da atualidade. Como nós nos apercebemos apenas da dimensão atual, percecionamo-la como algo desestruturado. Mas, segundo o autor, enganamo-nos. "A moda, diz-se, tem horror ao sistema. Uma vez mais o mito inverte de forma muito precisa o real: a moda é uma ordem da qual se faz uma desordem. Como se opera essa conversão do real em mito? Pela retórica da moda" (Barthes 1983: 302). O ponto de partida de Sapir, pensar a moda como sendo um costume que se mascara de um afastamento face ao costume, é retomado por Barthes - embora a partir de uma outra argumentação, fundamentada no estudo detalhado de textos e imagens publicadas em revistas de moda.

Mas o novo da moda parece ter na nossa sociedade uma função antropológica bem definida e que resulta da sua ambiguidade: ao mesmo tempo imprevisível e sistemático, regular e desconhecido, aleatório e estruturado, ele conjuga fantasticamente o inteligível sem o qual os homens não poderiam viver e a imprevisibilidade ligada ao mito da vida. (Barthes 1983: 302)

Dizer que a moda é um fenómeno social que surge de forma mais evidente nas sociedades ditas "ocidentais" (e que, segundo os historiadores, terá tido a sua origem na renascença e no advento da modernidade) é hoje mais ou menos consensual. No entanto, como se pode depreender das propostas conceptuais até agora referidas, a moda parece conter em si uma lógica que pode ser mais universal. Era essa a convicção de André Leroi-Gourhan, que afirmou, em 1945, que "a moda, no que ela tem de mais inconstante, não é o privilégio do Ocidente moderno: todos os povos, por pouco que os tenhamos seguido durante meio século, apresentam variações consideráveis e rápidas" (Leroi-Gourhan 2017: 195).

Inserida no campo do estudo das técnicas, esta proposta é construída a partir de uma distinção importante entre o que muda e o que se mantém na roupa. A técnica do vestuário é, segundo ele, uma técnica de transformação lenta. Porque tem de responder à função específica de cobrir o corpo humano, a técnica fica constrangida pela sua anatomia. Para cobrirem o corpo, as roupas têm de utilizar os pontos de apoio que o mesmo fornece, pelo que as respostas 
já encontradas não serão facilmente substituíveis. Mas o trajar responde também a uma outra função, a de enfeitar ou adornar (parer). O que muda, em todas as sociedades, prende-se basicamente com esta segunda função: "A roupa está portanto em perpétua transformação, mas essa transformação tem felizmente limites: ela incide mais frequentemente sobre o lado da parure e atinge pouco o lado da proteção.” (Leroi-Gourhan 2017: 195-96)

A distinção feita por Leroi-Gourhan foi importante no âmbito do estudo das técnicas, tendo tido também repercussões noutras perspetivas de trabalho. Roland Barthes, que o cita, está bem consciente da pequena variabilidade, ao nível daquilo a que chama a "estrutura tecnológica”, das componentes que respondem à função de proteção, e da significativa variabilidade das componentes que respondem à função do adorno. Variar cores, tamanhos e formas de golas, larguras e alturas de saias ou de calças é possível, mantendo, no entanto, a lógica de base de ligação da forma da roupa à anatomia do corpo. É por isso que a produção de sentidos se ancora sobretudo naquilo que pode ser sujeito a constantes variações: a parte da estrutura tecnológica que se prende com a parure.

Umberto Eco, que em vários momentos refletiu sobre o vestir, iniciou assim um texto escrito em 1969:

Quem se interessou alguma vez pelos atuais problemas da semiologia, já não pode continuar a fazer o nó da gravata, todas as manhãs diante do espelho, sem ficar com a clara sensação de estar a fazer uma opção ideológica: ou, pelo menos, de lançar uma mensagem (...) a todos os que se cruzarem com ele durante o dia. (Eco 1982: 7)

Tratar o vestir como um ato de comunicação foi uma tarefa que vários investigadores tentaram levar a cabo a partir dos anos 1960. Os códigos de vestuário foram descritos e interpretados, tanto por historiadores, como por antropólogos, sociólogos e semiólogos. Mas o que o texto de Umberto Eco já continha de novo no fim dos anos 1960, era, por um lado, a questão da autoconsciência relativa aos efeitos comunicativos do vestir (que só na década de 1990 será tratada a partir de quadros conceptuais consistentes) e, por outro, a questão da mudança rápida desses mesmos códigos (que obriga a dotar a lógica interpretativa de uma grande flexibilidade).

O ponto que nos interessa realçar é que existem códigos de vestuário. Só que são extremamente flutuantes, de modo que o analista do vestuário que queira introduzir as opções ideológicas ou psicológicas dos comportamentos de maneira de vestir, deve estar pronto a tomar os códigos enquanto se manifestem e imediatamente desfaçam. (Eco 1982: 20)

Mais tarde, dois antropólogos, Marshall Sahlins (1976) e Grant McCracken (1988), vieram a abordar, de formas diferentes das da semiologia, a questão dos sentidos das roupas. Sahlins desenvolveu, através do sistema de vestuário norte-americano, o argumento de que a produção capitalista é formulada a partir de um sistema cultural. É nesse sentido que o valor funcional da roupa é definido por um sistema significativo que, de acordo com o autor, tem seu pressuposto validado no pensamento totêmico levistraussiano. Sahlins utiliza a expressão "totemismo burguês", ao se referir a uma complexidade maior na definição de simbolismos originalmente tratados por Levi-Strauss. O autor, então, desenvolve um esquema de funções significadas no vestuário norte-americano, partindo da oposição, significativa nas roupas, de lazer versus trabalho. Por seu lado, Grant McCracken (1988), num capítulo de "Culture and consumption", defende que não é possível fazer uma analogia entre a linguagem e os modos de vestir. Descarta essa metodologia, mas considera a moda como um sistema que cria e transfere sentidos, graças 
basicamente a três mecanismos: conexão de sentidos criados nas roupas com o mundo cultural, criação de novos sentidos culturais e criação de formas radicais.

Como pano de fundo de tudo o que ficou dito, está a questão da contemporaneidade, do ser do seu tempo, abordada por Giorgio Agamben numa conferência em 2005. Tal como a modernidade a constituiu, a contemporaneidade implica sempre uma deslocação, uma distanciação crítica face ao tempo presente. Ser do seu tempo é não coincidir exatamente com ele. Segundo Agamben, a moda é um exemplo da experiência particular do tempo a que chamamos contemporaneidade: "O tempo da moda está portanto, de maneira constitutiva, em avanço face a si próprio, e por essa mesma razão, também sempre em atraso; ele tem sempre a forma de uma inacessível fronteira entre o 'pas encore' e o 'ne plus"' (Agamben 2008: 29).

É nesse desajuste que a criatividade e, por vezes, a diferença associada a verdadeiras transformações dos costumes, se alojam. O facto de a normatividade da moda conter em si a possibilidade de pôr em causa a norma vigente traduz-se, como referem alguns dos autores citados, no aparecimento de mudanças que não são, ao contrário do que parecem, estruturais; mas esse mesmo facto permite também o aparecimento, e até a institucionalização, de mudanças que, do ponto de vista social e cultural, se podem revelar estruturalmente significativas.

\section{CORPOS VESTIDOS}

Terence S. Turner publicou, em 1980, um texto intitulado “The Social Skin”, apoiado numa etnografia realizada entre os Kayapo, mas cujo objectivo é pensar a questão da universalidade, no humano, do uso das roupas ou de algo simbolicamente equivalente. Segundo ele, o adorno e a apresentação pública do corpo é, para todas as culturas, apesar da sua aparente inconsequência ou frivolidade, uma coisa séria (no sentido que Durkheim dá à expressão la vie sérieuse, para falar de religião) (Turner 2012: 486). Turner considera a presença de múltiplos recursos nos mecanismos de construção das identidades, sendo que "a vestimenta e o adorno corporal constituem um desses meios culturais, talvez o mais especializado na modelagem e comunicação da identidade pessoal e social. (Turner 2012: 487)”.

A afirmação da existência de uma relação entre as roupas e as identidades (pessoais, de linhagem, de classe, de género ...), bem como o entendimento do seu papel nos processos de negociação identitária, será provavelmente o legado mais óbvio da Antropologia para o estudo da roupa e da moda. ${ }^{6}$ Esse legado implicou, sobretudo a partir dos anos 1990, compreender também o que se estava a passar com a construção dos corpos.

Em 1990, David Le Breton publicou um livro intitulado "Anthropologie du corps et modernité", onde tentou definir o que mudou radicalmente na construção da ideia de pessoa, a

\footnotetext{
6 Em 1936, sem a intenção de elaborar um enfoque mais denso acerca do vestuário, Gregory Bateson (1971), como resultado da sua etnografia entre os Iatmuls, observou no ritual Naven a inversão do uso indumentário entre os géneros. $\mathrm{O}$ antropólogo foi quem primeiro empregou o termo ethos no sentido da expressão dos aspectos afetivos padronizados, e, retomando a sua experiência entre os Iatmuls, o ethos de um comportamento de género.
} 
partir dos anos 1960. Ao contrário do que se passava nas sociedades tradicionais, em que o corpo não se distingue da pessoa, o corpo moderno implica, segundo o autor,

o corte do sujeito com os outros (uma estrutura social de tipo individualista), com o cosmos (as matérias primas que compõem o corpo não têm nenhuma correspondência alhures) e consigo próprio (ter um corpo, mais do que ser o seu corpo). (Le Breton 1990:8)

É certo que desde que, em 1936, Marcel Mauss formulou a teoria das técnicas corporais, o corpo é, para os antropólogos, indiscutivelmente uma construção social e cultural, que resulta, como Pierre Bourdieu (1979) veio mais tarde reafirmar, ao propor a noção de habitus, de práticas quotidianas socialmente padronizadas. Mas o que aparentemente se alterou, com o aparecimento do chamado corpo moderno, foi a relação dos indivíduos com o processo de construção identitária em que o corpo está envolvido. Ele passou a ser mais consciente, e esse facto levou-os a conceber o seu corpo como uma exterioridade (o meu corpo) modelável. As técnicas de construção do corpo passaram assim a integrar, tal como as roupas, a aparelhagem disponível para concretizar, no interior de uma lógica de construção reflexiva das identidades, os body projects dos sujeitos da modernidade tardia (Giddens 1991).

Cabe aqui referir o cruzamento, fecundo para as perspetivas contemporâneas, entre a antropologia e a proposição da denominada Self-presentation theory, de Erving Goffman (1956). Interessado numa microssociologia da vida quotidiana, ele desenvolve uma "abordagem dramatúrgica”, na qual valoriza a ideia de performance para o entendimento das interações sociais. No seu hoje clássico "The Presentation of Self in Everyday Life", desenvolve o tema diferenciando os veículos fixos de apresentação (corpo, etnia, etc.) dos veículos não-fixos (vestuário, acessórios e outros itens facilmente gerenciados para uma estratégia imagética). Na elaboração da apresentação pessoal, de acordo com o autor, os sujeitos operam monitorando as expectativas da "plateia", em geral, buscando a credibilidade, ponto-chave para avaliar uma performance bem-sucedida.

A partir dos finais da década de 1960, a antropologia começou a articular ritual, práticas artísticas e vida quotidiana no interior do campo de estudos que hoje denominamos por "antropologia da performance" (Schechner 1988). Os seus autores colocam o corpo e a materialidade no interior dos "eventos", dando particular relevância à interatividade (uma performance existe enquanto ação, interação e relação) e, consequentemente, aos fluxos. Os estudos de moda cruzam-se hoje com esta perspetiva, tanto para trabalhar acontecimentos como os desfiles de moda e as passadeiras vermelhas, como para trabalhar, na senda de Goffman, as lógicas quotidianas da construção de si.

A partir dos finais da década de 1980, a moda vai-se integrar num outro quadro de reflexão antropológica. Os estudos de cultura material passaram então a colocar os objetos de consumo no interior de propostas conceptuais que, de formas diversas, pretenderam ultrapassar a dicotomia pessoa/objeto. Daniel Miller (1987) afirmou-se como uma figura central desse movimento, contribuindo, com a proposta e a operacionalização da noção de "objectificação", para o entendimento do papel que as coisas assumem na construção das identidades. Nesse contexto intelectual, em que a cultura contemporânea passou a ser considerada como uma cultura em que a materialidade tem uma presença considerável, as roupas e os acessórios surgiram como objetos de estudo antropológico incontornáveis - porque se considerarmos, como Miller propõe, que os objetos são constitutivos dos sujeitos, as roupas e os adornos, por fazerem um todo com o corpo, assumem com certeza uma relevância especial no interior desse processo. 
Annette B. Weiner desenvolveu um trabalho que se viria também a revelar importante para os estudos de cultura material, e, mais em particular, para a afirmação da importância do estudo das roupas. $\mathrm{Na}$ sua revisitação dos Trobriandeses ("The Trobrianders of papua new Guinea"), Weiner (1988) deu especial atenção ao estudo dos objetos e às suas relações com o poder e com a ritualização de emoções intensas. Para lá dos objetos que integram a prática do Kula (as embarcações, as conchas, os braceletes), Weiner interessou-se por outros objetos, aos quais Malinowski não tinha dado particular atenção: uns molhos e umas saias feitos de fibras de bananas. São objetos associados às mulheres, importantes agentes nos rituais fúnebres e de grande importância para a definição dos lugares políticos das matrilinhagens. Posteriormente, Weiner (1989 e 1994) viria a trabalhar sobre tecidos, roupas e mulheres em diferentes contextos, tendo defendido, com base nesses trabalhos, a existência, em diferentes conjunturas, de uma relação entre os tecidos, as mulheres e o poder:

De uma sociedade para outra, esse poder pode ser dirigido para rumos particulares, nalguns casos colocando a mulher em proeminência política, noutras situações suportando a hegemonia masculina. Mas a extensão da densidade simbólica no tecido e o envolvimento de mulheres na sua produção e controlo são uma medida de como este poder com base no género é organizado. (Weiner 1994: 397)

$\mathrm{Na}$ viragem do século $\mathrm{XX}$, surgiu um outro legado conceptual da antropologia para os estudos sobre roupa e moda: o uso da palavra dress (em vez de clothing), num sentido que foi formulado pela antropóloga Joanne B. Eicher. O Texto que então publicou tem por título "The Antrhropology of Dress", campo que a autora define como sendo, simplesmente, o estudo do vestir pelos antropólogos (Eicher 2000:59). A sua proposta, dada a deslocação do enfoque do nome (roupas, vestes) para o verbo (vestir), ajudou a construir uma outra forma de entendimento do tema. Como referem Lise Skov e Marie Riegles (2010), dress tornou-se num conceito chave para investigadores de diversas proveniências disciplinares, porque permite integrar no mesmo campo analítico as roupas (objetos dominantes do vestir ocidental), os adornos corporais (antes percecionados como mais "primitivos") e a dimensão performativa das práticas incorporadas. Por ser mais neutral face às hierarquias culturais que outros conceitos, dress revelou-se particularmente eficaz nas investigações que decorreram já em contexto de pós-globalização. Em 2004, Karen Tranberg Hansen publicou um texto intitulado "The world in dress: anthropological perspectives on clothing, fashion, and culture", em que reafirmou a importância deste ponto de vista englobante, onde se inserem hoje a maioria das investigações antropológicas. ${ }^{7}$

Retornamos aos estudos de cultura material, para referir ainda alguns dos aportes de Daniel Miller para o campo dos dress and fashion studies. Na obra "Clothing as material culture", que edita e onde assina a introdução, Miller (2005 a) torna claro que as qualidades materiais das roupas - fibras, padrões, formas - são parte intrínseca do seu compromisso humano e cosmológico. "O sensual e o estético - o toque do tecido e a sua aparência - é a fonte da sua capacidade para objectificar o mito, a cosmologia e também a moralidade, o poder e os valores." (Miller, 2005 a: 1)

Este é um posicionamento importante porque obriga a observar e a estudar as coisas também na sua materialidade. $\mathrm{Na}$ verdade, uma parte significativa das abordagens feitas à moda e às roupas invisibilizou a existência destas enquanto matérias. É o caso do texto de Pierre Bourdieu e Yvette Delsault (1975) "Le couturier et sa griffe: contribution à une théorie de la

$7 \quad$ No caso de Portugal, Valter Cardim foi pioneiro, apresentando na NOVA FCSH, em 1998, uma tese em antropologia sob o título "Fashion, design, cultura e identidade. A costura social da moda em Portugal no século XX". 
magie", que, ao tentar desmontar o mecanismo de produção do valor simbólico das roupas de alta costura, anula a existência material das mesmas, porque se recusa a considerar as qualidades físicas, construtivas e formais como fatores intrínsecos ao funcionamento do referido mecanismo. Reposicionar a matéria no interior da relação pessoa/objeto é uma tarefa que a antropologia tem vindo a fazer nos últimos anos, com propostas conceptuais diversificadas e até discordantes (Alfred Gell, Bruno LaTour, Tim Ingold), mas que têm em comum a reaproximação, tanto ao nível da observação como ao nível da conceptualização, à materialidade das coisas. $\mathrm{Na}$ introdução a uma outra obra, "Materialy", Miller (2005b) fala de um fenómeno integral que é o clothing/person (roupa/pessoa). Esse fenómeno é experiencial, emocional, social e cultural. Apesar de concebermos o nosso corpo, através de trânsitos associados à autorreflexão, como uma exterioridade que podemos modelar, nós somos ele. No fluxo performativo que é a nossa existência, nós somos as transformações que lhe fazemos, as roupas com que o vestimos e os objetos com que o adornamos.

Uma mulher que habitualmente veste sari, comparada com uma que veste roupas ocidentais ou uma shalwar kamiz, não é apenas uma pessoa vestida com um sari. Porque o dinamismo e as demandas do sari podem transformar tudo, desde a maneira como ela encontra outras pessoas, até à sua forma de conceber o que é ser moderno ou racional. (Miller 2005b:18)

A proposta conceptual e teórica que decorre dessa vontade de ultrapassar a oposição pessoa/objecto, quando focada no vestir, coincide com a consciência reflexiva que alguns atores sociais expressam, sobretudo nos campos da arte, da moda e da política identitária. Veja-se a célebre frase da Drag Queen RuPaul, que escolhemos como epígrafe para esta introdução: "Nascemos nus e o resto é drag". ${ }^{8}$

A nossa existência enquanto sujeitos com identidades culturais e sociais é feita, desde o início, com e pelas roupas. Mesmo, como Miller demonstra a partir de dois tipos de indumentária, quando vestir-se é uma opção de normatividade e de não diferenciação. Uma parte das mulheres emigrantes que chegam a Londres optam por vestir jeans, nas suas versões mais simplificadas e uniformizadas, exatamente porque pretendem diluir-se no anonimato da cidade. "Isto é porque os jeans se tornaram provavelmente na primeira roupa pós-semiótica, no sentido de não indicarem nada senão a sua vulgaridade, o que corresponde a um dos ideais da ecúmena global" (Miller 2010:421). Num certo sentido, o mesmo acontece com a opção, em contexto social sofisticado, pelo simples vestido preto. Como refere Miller (2004), num texto intitulado "The little black dress is the solution. But what's the problem?", a liberdade que conquistámos para nos vestirmos sem normas estritas cria a ansiedade do resultado que as nossas escolhas podem ter em sociedade. E como "com o meu vestido preto eu nunca me comprometo ...", ele é a solução.

8 RuPaul Andre Charles é uma drag queen americana presente na cena artística de Nova Iorque desde a década de 1990. É actor, cantor, modelo, letrista e apresentador de televisão. Em 2017, foi incluído na lista Time 100 das pessoas mais influentes do mundo. O campo semântico da palavra drag é vasto; segundo alguns autores tem origem no teatro isabelino e hoje integra teatro, roupa, representação, travestismo, vestir, homossexualidade. 


\section{COMO SE FAZ A MODA}

No percurso que tentámos aqui traçar, relativo às articulações entre a antropologia e o estudo da moda, aparecem muito poucos trabalhos relativos àquilo que comummente se chama o "mundo da moda". Ou seja, ao campo restrito onde interagem as pessoas que se relacionam directamente com a produção e a distribuição de roupas, acessórios e imagens de moda. As etnografias sobre esse "mundo" são ainda poucas, mas nas últimas décadas começaram a multiplicar-se. Para finalizar este texto, fazemos aqui referência, embora de forma pontual, a alguns desses trabalhos, com a intenção de assinalar temáticas recentemente trabalhadas e que, tudo indica, terão continuidade no seio da antropologia contemporânea.

Como vimos, as respostas encontradas, nas últimas décadas, pela antropologia para trabalhar a temática do vestir inserem-se hoje numa problemática mais geral relativa à cultura material e à relação entre as pessoas e as coisas, que integra as matérias na construção do sujeito. Sendo que a ideia de "materialidade", tal como Miller a formula, pretende também ultrapassar o dualismo material/imaterial, dando igual relevância às dimensões materiais e às dimensões simbólicas e discursivas das coisas. A relação que se estabelece entre as pessoas e as roupas - as que elas próprias vestem, ou as que os outros, com quem elas se relacionam, vestem - integra ambas as características.

O estudo da moda enquanto cultura material implicará fazer um outro ajuste epistemológico, que se insere no mesmo movimento intelectual, mas que diz respeito, desta vez, não ao consumo mas à produção e, mais concretamente, ao fazer. Neste caso - e seguindo as reservas que Ingold (2007) manifesta face a abordagens dos objectos que considera demasiado metafísicas - dando maior atenção à prática técnica, aos processos de transformação dos materiais e da matéria, bem como aos modos de pensar e de ser daqueles que os executam (Coupaye e Douny 2009). No seguimento das propostas, entre outros, de Jean-Pierre Warnier (1999), Richard Sennett (2008) e Susanne Kuchler (2009), focando-se nos processos intersubjectivos subjacentes às aprendizagens das técnicas, sempre feitas na prática e que - tal como acontece com a prática do vestir - se enraízam nos sujeitos: quando um corpo transforma uma matéria, essa mesma matéria, por sua vez, transforma esse corpo e, consequentemente, o sujeito que opera sobre a matéria.

A produção contemporânea de moda abarca um leque muito diversificado de profissões, de técnicas e de práticas, que vai dos saber-fazer artesanais da alta-costura francesa, até às tecnologias industriais de ponta japonesas, passando pelo design, pela fotografia, pelo pousar e pelo desfilar (entre muitas outras). Num número recente da revista Terrains/Théories intitulado "La fabrique de la mode", Anne Monjaret e Kristell Blache-Comte (2018), as organizadoras, referem, na introdução, a escassez de trabalhos sobre o mundo da moda, fazendo no entanto um levantamento dos textos de etnologia das técnicas realizados em contexto francês, que mostra bem que, apesar de circunscrito, há um interesse recente da antropologia pelo estudo do fazer no campo da moda. Os quatro textos publicados no referido número são também reveladores dessa mesma tendência. Partindo de um posicionamento conceptual que integra dimensões mais globais - precaridade das relações laborais, valorização simbólica, mas não monetária, do trabalho, papel da família nas dinâmicas empresariais, nomeadamente nas transnacionais - surgiram recentemente dois trabalhos que se destacam pela riqueza das etnografias que os sustentam: um levado a cabo em Paris por Giulia Mensitieri (2018) e outro em Itália e na China por Lisa Rofel e Sylvia J. Yanagisako (2019. 
Fazemos referência, por fim, a uma auto-etnografia realizada pela designer de moda canadiana Alexandra Verschueren (2013). Com base numa descrição detalhada do processo produtivo de cinco colecções, a autora dá-nos acesso, socorrendo-se de uma notável auto-reflexividade, ao normalmente impenetrável mundo da criação de moda, revelando como as interacções entre as imagens, as ideias e as matérias operam na sua própria prática criativa.

\section{BiBLIOGRAFIA}

Agamben, Giorgio. 2008. “Qu'est-ce que le contemporain”. Paris: Rivages.

Barthes, Roland. 1983. Système de la Mode. Paris : Éditions du Seuil (Primeira edição 1967).

Bateson, Gregory. 1971. La Cérémonie du Naven. Paris: Minuit (Primeira edição 1936).

Blumer, Herbert. 1969. "Fashion: from class differentiation to collective selection". Pp.275-91 em Sociological Quarterly 10, n³.

Bourdieu, Pierre e Yvette Delsault. 1975. "Le couturier et sa griffe: contribution à une théorie de la magie". Pp.7-36 em Actes de la recherche en sciences sociales - Hiérarchie sociale des objets, Vol. 1, n¹, janvier 1975.

Bourdieu, Pierre. 1979. La Disctinction. Critique sociale du jugement. Paris: Minuit.

Coupaye, Ludovic e Laurence Douny. 2009. "Dans la trajectoire des choses”. Pp. 12-39 em Techniques E Cultures 52-53.

Durkheim, Émile. 1887. “La science positive de la morale en Allemagne”. Pp.33-58 em Revue philosophique de la France et de l'étranger.

Eco, Umberto. 1982. "O hábito fala pelo monge". Pp. 7-20 em Psicologia do vestir. Lisboa: Assíro e Alvim (Primeira publicação 1969).

Eicher, Joanne. 2000. “The Anthropology of Dress”, Dress, Volume 27: 59-70.

Featherstone, Mike. 2007. Consumer Culture and Postmodernism. London: Sage Publications.

Giddens, Anthony. 1991. Modernity and Self Identity. Oxford: Polity.

Goffman, Erving.1956. The Presentation of Self in Everyday Life. Edinburgh: University of Edinburgh, Social Sciences Research Centre.

Hammen, Émilie e Benjamin Simmenauer. 2017. Les grands textes de la mode. Paris: Éditions du Regard.

Hansen Karen, 2004, «The world in dress: anthropological perspectives on clothing, fashion, and culture ", Annual Review of Anthropology, vol.33 : 369-392.

Ingold, Tim. 2007. "Materials againts materiality". Archaeological dialogues 14 (1): 1-16

Kroeber, Alfred e Jane Richardson. 1940. "Three centuries of women's dress fashion : a quantitative analysis", Anthropological Records 5, no2 :111-153.

Kuchler, Susanne e Graeme Were, 2009, "Empathie avec la matière - Comment repenser la nature de l'action technique", Techniques E' Culture, no52-53: 190-211.

Le Breton, David. 1990. Anthropologie du corps et modernité. Paris: PUF.

Leroi-Gourhan, André. 2017. "Milieu et technique”. Pp. 194-199 em Hammen, Émilie e

Lipovetsky, Gilles. 1987. L'empire de l'éphémère - la mode et son destin dans les sociétés modernes. Paris: Gallimard.

Mauss, Marcel.1974. Sociologia e Antropologia volume II. São Paulo: E.p.u. - edusp. (Primeira edição 1950)

McCracken, Grant. 1988. Culture and consumption. Bloomington: Indiana University Press.

Mensitieri, Giulia. 2018. "Le plus beau métier du monde" - dans les coulisses de l'industrie de la mode. Paris: éditions la découverte. 
Miller, Daniel. 1987. Material culture and mass consumption. Oxford: Blackwell.

Miller, Daniel, 2005a, "Introduction ». Pp.1-13 em Clothing as Material Culture, editado por D. Miller e S. Küchler. Oxford: Berg.

Miller Daniel, 2005b, « Introduction ». Pp.1-50 em Materiality, editado por D. Miller. Durham e London: Duke University Press.

Miller, Daniel. 2010. "Anthropology in blue jeans". AMERICAN ETHNOLOGIST, Vol. 37, No. 3: 415-428.

Miller, Danial. 2004. "The little black dress is the solution. But what's the problem?”. Pp. 113127 em Elusive consumption, editado por K. Ekstrom e H. Brembeck. Oxford: Berg.

Monjaret, Anne, Kristell Blache-Comte, "Introduction", Terrains/Théories [En ligne], 8 | 2018, mis en ligne le 07 novembre 2018, consulté le 07 mars 2019. URL : http://journals.openedition.org/teth/1173

Polhemus, Ted. 1978. Fashion and anti-Fashion: an anthropology of clothing and adornment. London: Cox and Wyman.

Rofel, Lisa, Sylvia J. Yanagisako. 2019. Fabricating transnational capitalismo. Durham e London: Duke University Press.

Sahlins, Marshall. 1976. Culture and Practical Reason. Chicago: University of Chicago Press.

Sapir, Edward. 2017. "Fashion”. Pp.123-127 em Hammen, Émilie e Benjamin

Sennett Richard, 2008, The craftsman, New Haven, Yale University Press.

Spencer, Herbert. 1882, Manners and Fashion, em Fashion in deformity, edited by Flower, W.H.. Nova Iorque: Humboldt Publishing Co.. (Primeira edição 1854).

Schechner, Richard. 1988. Performace theory. London: Routledge.

Simmel, Georg. 1988. "La mode ». Pp. 88-126 em Georg Simmel, La tragédie de la culture et autres essais. Paris : Rivages (Primeira edição 1895).

Skove, Lise e Marie Riegles. 2010. "Research Approaches to the Study of Dress and Fashion," em The Berg Encyclopedia of World Dress and Fashion, edited by Joanne B. Eicher. Oxford: Berg.

Tarde, Gabriel. 1890. Les lois de l'imitation. Étude Sociologique. Paris: Felix Alcan Éditeur.

Turner, Terence. 2012. "The social skin”, Jornal of Ethnographic Theory 2 (2): 486-504. (Primeira edição 1980)

Veblen, Thorstein. 1994. The Theory of the Leisure Class. New York: Dover Publications (Primeira edição 1899).

Verschueren, Alexandra. 2013). The autoethnography of creative design: From Medium to Shift. Disponível em http://fashion.semiotix.org/2013/02/the-autoethnography-of-creative-design-from-medium-to-shift/

Warnier, Jean-Pierre. 1999. Construire la culture matérielle: l'homme qui pensai avec ses doigts. Paris :PUF .

Weiner, Annette. 1988. The Trobrianders of Papua Nerw Guinea. Belmont: Wadsworth.

Weiner, Annette. 1994. "Cultural Difference and the Density of Objects",American Ethnologist, Vol. 21, No. 2 (May, 1994): 391-403.

\section{ENCOUNTERS BETWEEN FASHION AND ANTHROPOLOGY: BEGINNINGS, Debates AND PERSPECTIVES}

This article aims to approximate the look towards fashion as an object of research, analysis and reflection in the field of anthropology. The complexity of the theme drives the debate through the paths of 
the transdisciplinarity, in an effort to enrich and to clarify the discussion. Authors that are positioned in the field of the philosophy, sociology, semiology and linguistics dialogue with the anthropology, moving through problematic themes as the construction of identities and the relationship with time. Furthermore, it seeks to rescue reflections that bring light to recent debates about fashion as corollary of imitation and distinction, performances, forms body building, the socio-economic dynamics and materiality. In order to address chronologically the encounter between anthropology and fashion studies, the text leaves from the beginnings (first half of the 20th century), passing through current debates and, finally, pointing out the perspectives that those new studies add to the field.

Keywords: fashion, imitation, distinction, body, performance, materiality 